\title{
Retos del periodismo ante el nuevo escenario digital
}

\author{
Pablo López Rabadán \\ Universitat Jaume I \\ Marcial Murciano Martínez \\ Universitat Autònoma de Barcelona
}

La sección Informe del número 4 de adComunica. Revista Científica de Estrategias, Tendencias, e Innovación en Comunicación está dedicada al estudio de los retos a los que se enfrenta actualmente el periodismo en un escenario caracterizado por la transformación digital.

La irrupción de Internet como plataforma informativa ha generado en la última década profundos cambios en todo el sector periodístico, afectando tanto a su estructura económica tradicional como a sus sistemas de producción y distribución de contenidos. Por una parte, la viabilidad del modelo de negocio de los medios, especialmente en el caso de la prensa, se encuentra gravemente amenazado por la caída de la venta directa y el gasto publicitario, agravado en un contexto de fuerte y prolongada crisis económica global. Además, la creciente influencia de medios y dispositivos digitales ha provocado también un gran impacto en su modelo de gestión profesional, muy necesitado de redefinir sus objetivos y superar una notable pérdida de identidad y credibilidad entre la ciudadanía.

Ante esta coyuntura, el periodismo debe afrontar un imprescindible proceso de renovación a nivel empresarial, profesional y ético que le permita seguir cumpliendo sus importantes funciones sociales, integrado dentro de mercados cada vez más competitivos, y ante públicos más exigentes y autónomos.

Por todo ello, este monográfico se plantea como un espacio de reflexión y debate científico en torno a cuatro importantes retos de futuro para el sector periodístico: la propuesta de nuevos modelos de negocio viables (1), la actualización de su modelo profesional a las nuevas demandas sociales de calidad informativa (2), el 
desarrollo de nuevos contenidos y formatos que aprovechen las potencialidades del contexto digital (3); y la incorporación al proceso periodístico de las aportaciones de públicos cada vez más participativos (4).

En este sentido, la sección Informe del presente número de la revista adComunica recoge cinco trabajos de investigadores nacionales e internacionales interesados en el futuro del periodismo desde una perspectiva científica amplia y actualizada.

En primer lugar, Santiago Justel, de la Universitat Ramón Llull, presenta un estudio que reflexiona sobre la situación actual del modelo de negocio de las empresas informativas, a partir de material teórico y entrevistas en profundidad a profesionales del sector. En su artículo, Transformación en la audiencia, transformación en los medios: un marco para el estudio de los retos y estrategias de las empresas periodísticas, el autor analiza las posibilidades que ofrece actualmente la tecnología digital para lograr un mejor conocimiento del comportamiento del público, y su potencialidad para redefinir el modelo empresarial a partir de esta información estratégica.

También dentro del debate sobre nuevos modelos de negocio, en segundo lugar, Jesús Segarra, de la Universidad de Alicante, Patricia Páramo, del Diario Información, y Belén Puebla, de la Universidad Rey Juan Carlos, plantean un artículo que revisa otra interesante alternativa profesional, el desarrollo de la emprendeduría y la puesta en marcha de proyectos propios de microperiodismo. En concreto, los autores, en su texto Jóvenes emprendedores y sus proyectos de Comunicación en la red: estudio de caso de Periodistas en potencia y Portal del Sur, profundizan en el análisis del contenido y el planteamiento profesional de diferentes iniciativas puestas en marcha en los últimos años en Madrid por estudiantes y nuevos titulados en periodismo.

En tercer lugar, Salomé Berrocal, Marta Redondo, y Eva Campos, de la Universidad de Valladolid, presentan un completo estado de la cuestión sobre una importante tendencia transversal dentro del debate sobre los nuevos contenidos y formatos periodísticos: el desarrollo del infoentretenimiento en los medios digitales. En su artículo Una aproximación al estudio del infoentretenimiento en Internet: origen, desarrollo y perspectivas futuras, las autoras ofrecen un diagnóstico actual de este fenómeno en la academia española, y a partir de una revisión cualitativa a la literatura teórica al respecto, proponen una serie de líneas de investigación sobre las que profundizar a corto y medio plazo.

Vinculado también al estudio del infoentretenimiento encontramos en cuarto lugar el artículo de Carles Marín, de la Universidad Rey Juan Carlos, La pérdida de objetividad en las noticias de los programas de infoentretenimiento en televisión. En este caso, el autor ofrece una revisión del fenómeno aplicado específicamente al caso del medio televisivo en España y las transformaciones que viene generando en sus contenidos. A partir del análisis cualitativo de varios ejemplos de programas informativos actuales, Marín profundiza en la descripción de sus 
principales características formales y la explicación de sus consecuencias respecto a una cualidad periodística básica como es la búsqueda de la objetividad.

Y por último, en quinto lugar, Loïc Ballarini, de la Université París 8 (Francia), presenta un artículo que reflexiona sobre la vigencia actual de la prensa regional en Francia y su muy relevante recepción entre todo tipo de lectores, en un contexto de progresivo declive del resto de diarios y revistas a nivel nacional. En su texto titulado, ¿Por qué leer la prensa regional hoy en día?, Ballarini aporta varias claves para entender la consolidación de este tipo de periodismo, y sus implicaciones como dinamizadora del espacio público local, a partir del análisis específico de los contenidos de la prensa bretona y los resultados de una serie de entrevistas en profundidad.

En resumen, confiamos que este conjunto de trabajos contribuya a enriquecer el necesario debate científico sobre los desafíos a los que se enfrenta actualmente el periodismo. Más allá de los cambios estructurales y las importantes dificultades que atraviesa el sector, entendemos también el contexto actual como una interesante oportunidad de repensar el periodismo del futuro con una fuerte base tecnológica, pero bien articulado profesionalmente y consciente de sus funciones sociales y democráticas.

\section{Referencia de este artículo:}

López Rabadán, Pablo y Murciano Martínez, Marcial (2012). Retos del periodismo ante el nuevo escenario digital. En: adComunica. Revista Científica de Estrategias, Tendencias e Innovación en Comunicación, $\mathrm{n}^{0} 4$. Castellón: Asociación para el Desarrollo de la Comunicación adComunica, Universidad Complutense de Madrid y Universitat Jaume I, 17-19. DOI: http://dx.doi.org/10.6035/21740992.2012.4.2 